Research Article

\title{
Subloading Surface Model and Experimental Study of Coal Failure under Cyclic Loading
}

\author{
Si-fei Liu, Zhi-jun Wan (D), Jing-chao Wang, Shuai-feng Lu, and Tong-huan Li \\ Key Laboratory of Deep Coal Resource Mining (CUMT), Ministry of Education of China, School of Mines, \\ China University of Mining \& Technology, Xuzhou 221116, China \\ Correspondence should be addressed to Zhi-jun Wan; zhjwan@cumt.edu.cn
}

Received 28 November 2018; Revised 23 March 2019; Accepted 10 April 2019; Published 2 May 2019

Academic Editor: Alicia E. Ares

Copyright (c) 2019 Si-fei Liu et al. This is an open access article distributed under the Creative Commons Attribution License, which permits unrestricted use, distribution, and reproduction in any medium, provided the original work is properly cited.

The fatigue damage of rock is an important factor affecting the stability of rock structure. In this paper, the mechanical response of coal under cyclic loading was studied. In order to accurately describe the deformation characteristics of coal under cyclic loading, an elastic-plastic model of coal based on the theory of subloading surface was established and verified by experiments. The model can well reflect the Mancin effect and ratcheting effect of coal samples, which is basically consistent with the actual deformation characteristics of coal, and the theoretical value and experimental value are in good agreement. At the same time, the cyclic response characteristics of specimens under strain load disturbance were analyzed. The results show that the specific strain disturbance can only cause a certain damage to coal and the area of hysteresis loop decreases first, then stabilizes, and then increases as the number of cycles increases. In addition, the damage factor $D_{n}$ in the model was analyzed in this paper. $D_{n}$, which can accurately describe the damage process of coal, accurately locate the time point of disturbance load change, and has greater sensitivity to coal failure, is helpful to improve the accuracy of the stability judgment of coal structure and ensure the safety of engineering. The above results are of great significance for strengthening the understanding of coal mass instability process and mode under cyclic loading.

\section{Introduction}

The stability of rock structure is the key to ensuring safe mining. Rock has several failure modes, including shear failure, tensile failure, compressive failure, and fatigue damage failure, among which the first three modes have been extensively studied. Rock structure is subjected to cyclic loading constantly during mining, such as ore mining, mechanical drilling, truck transportation, and rock blasting. Rock is prone to fatigue damage under cyclic loading, which reduces the stability of roadways and excavation boundary and even causes the grave failure of rock mass. The problem of rock fatigue damage in engineering field can be explained and predicted more accurately by exploring the feature of rock fatigue damage. Therefore, the study on the effect of cyclic loading on rock damage has practical significance for the on-site production, which is why fatigue damage has become one of the hot issues in rock mechanics.
Scholars worldwide have noticed that the characteristics of rock damage and strength under cyclic loading differ from those under common pressure in early time, and they have conducted a large number of researches on mechanical response, damage evolution, and constitutive model of rock under cyclic loading. As to mechanical response, rock deformation under cyclic loading exhibits the pattern of "S-N" curve [1] and can be divided into three stages, namely, accelerated deformation, steady deformation, and accelerated deformation [2-7]. Scholars extensively studied elastic modulus and Poisson's ratio as well, which can be classified into three phases [8], namely, the phase of elastic modulus increase and Poisson's ratio decrease, the phase of elastic modulus decrease and Poisson's ratio minor increase [8] or being steady [9], and the phase of elastic modulus rapid decrease and Poisson's ratio rapid increase. Besides, some scholars redefined the stress characteristics of rock under cyclic loading to predict rock failure strength [10-13]. 
Compared with the rock under axial loading, rock under cyclic loading shows more fracture evolution pattern. In addition, researches indicate that cyclic loading enables the rock sample to generate wider fractures with more branches $[6,14,15]$ and enables mineral particles to detach from the matrix $[7,10]$, thus creating massive debris and fragments $[6,16,17]$. Studies show that acoustic emission phenomenon was rarely monitored during cyclic loading $[18,19]$, but some researchers believe that acoustic emission is well related to stress-strain [19]. Mancin and ratcheting effects, which are primary effects reflecting the constitutive model of rock under cyclic loading, are often simulated by using the multiyield surface plasticity framework $[20,21]$ and boundary surface plasticity model [22]. Hyperbolic backbone formulations, such as the modified Kondner-Zelasko model [23] and the general quadratic/hyperbolic model [15], are extensively used in rock cyclic loading. The abovementioned models boast practicality in simulating the dynamic response of rock under cyclic loading. However, their parameters are generally difficult to determine, and they lack clear physical meaning. In summary, the above contents are mostly research results of noncoal rocks, with little research on the mechanical response of coal under cyclic loading, especially on the instability process of coal. The coal wall is affected by the disturbance of mining machinery all the time. Therefore, it is necessary to strengthen the study on the effect of cyclic load on the mechanical properties of coal and its mechanism of action.

In order to study the mechanical response of coal under cyclic loading, the influence of cyclic loading on coal was grasped theoretically firstly. Then, an elastic-plastic model of coal based on the theory of subloading surface was established and verified by experiments. Besides, the disturbance signal in coal wall was applied to coal samples, and the development of hysteresis loop was observed. Finally, the difference of damage variables in different models was emphatically discussed.

\section{Constitutive Model of Cyclic Loading}

2.1. Basic Idea for Subloading Surface. The subloading surface was proposed by Hashiguchi [24] based on the deformation of metal materials under cyclic loading. The core idea of subloading surface is to assume that the current stress point always stays on a subloading surface which is located within and is geometrically similar to the normal-yield surface. Hence, the loading criterion does not need to judge whether the stress point is on the yield surface or not. This model not only shows the correlation between plastic strain increment and stress increment but also simulates the main cyclic loading characteristics of materials such as the Mancin and ratcheting effects. Moreover, compared with conventional models, the model boasts smooth transition from elastic stage to plastic stage, that is, it can obtain a continuous and derivable stress-strain relation curve.

The subloading surface model is shown in Figure 1. The yield condition of normal-yield surface is assumed to be



Figure 1: Subloading surface.

$$
f\left(\boldsymbol{\sigma}_{\mathbf{y}}\right)=F(H),
$$

where $\sigma_{\mathrm{y}}$, which is on the normal-yield surface, is the conjugate stress of the current stress on the subloading surface; $H$ is the hardening variable; $F$ is the subloading surface; and $f\left(\sigma_{\mathbf{y}}\right)$ is the expression of yield surface.

$$
f(\bar{\sigma})=R F(H),
$$

where $R$ denotes the similarity ratio of these surfaces and $\bar{\sigma}$ is the current stress on the subloading surface considering back stress of the subloading surface.

According to the geometric similarity,

$$
\begin{aligned}
& \bar{\sigma}=\boldsymbol{\sigma}-\bar{\alpha}=R \widehat{\sigma}_{\mathbf{y}}=R\left(\boldsymbol{\sigma}_{\mathbf{y}}-\alpha\right), \\
& \widehat{s}=s-\alpha=\frac{\bar{s}}{R}=\frac{s-\bar{\alpha}}{R}, \\
& \widetilde{\sigma}=\boldsymbol{\sigma}-\mathbf{s}=R \widetilde{\sigma}_{\mathbf{y}}=R\left(\boldsymbol{\sigma}_{\mathbf{y}}-\mathbf{s}\right),
\end{aligned}
$$

where $s$ denotes the similarity center; $\alpha$ is the geometrical center of the normal-yield surface; $\bar{\alpha}$ is the geometrical center of the subloading surface; $\widehat{\sigma}_{\mathrm{y}}$ is the conjugate stress of current stress $\boldsymbol{\sigma}$ on the subloading surface considering the back stress; $\bar{s}$ is the similarity center considering the back stress on the subloading surface; $\widetilde{\sigma}_{\mathrm{y}}$ is the vector difference of normal-yield surface stress and the similarity center; $\widehat{s}$ is the similarity center considering the back stress; and $\widetilde{\sigma}$ is the vector difference between subloading surface stress and the similarity center.

2.2. Elastic-Plastic Model under Cyclic Loading. Based on the conventional elastic-plastic model, the elastic-plastic modulus can be derived according to conformance conditions:

$$
\frac{\partial f}{\partial \bar{\sigma}} d \bar{\sigma}-F d R-R d F=0 .
$$

It can be known from equation (3)

$$
d \bar{\sigma}=d \boldsymbol{\sigma}-d \bar{\alpha}=d \boldsymbol{\sigma}-R d \boldsymbol{\alpha}-(1-R) d \mathbf{s}-d R \widehat{s} .
$$


The equation of similarity center $s$, similarity ratio $R$, and kinematic hardening $\alpha$ still needs to be determined.

The similarity center $s$ is analogous to the equation of subloading surface yield equation. Considering plastic deformation caused by cyclic loading, a new yield surface can be established based on the number of cycles $N$. Therefore, the yield equation of similarity center is

$$
f(\widehat{s})=R_{n} F(H),
$$

where $R_{n}$ is the ratio of the size of the similarity-center yield surface to the size of the normal-yield surface. According to the assumption that the similarity-center yield surface is within the normal-yield surface, equation (9) can be obtained by using the close condition of similarity center:

$$
d s-d \alpha-\frac{d F}{F} \widehat{s} \leq 0 .
$$

To satisfy equation (9), it is assumed that

$$
\begin{aligned}
d s-d \alpha-\frac{d F}{F} \widehat{s} & =C\left\|d \varepsilon^{\mathrm{p}}\right\|\left[\boldsymbol{\sigma}_{\mathbf{y}}-\alpha-\frac{R_{\mathrm{s}}}{\chi}\left(\mathbf{s}_{\mathbf{y}}-\alpha\right)\right] \\
& =C\left\|d \varepsilon^{\mathrm{p}}\right\|\left(\frac{\bar{\sigma}}{R}-\frac{\widehat{s}}{\gamma}\right),
\end{aligned}
$$

where $\chi$ is the maximum value of similarity-center ratio $R_{n}$; $C$ is the material parameter; $d \varepsilon^{\mathrm{p}}$ is the plastic strain; $\mathbf{s}_{\mathbf{y}}$ is the dual similarity center on the normal-yield surface of similarity center on the similarity-center yield surface; and $\sigma_{\mathbf{y}}$ is the conjugate stress of the current stress on the subloading surface:

$$
d s-d \alpha-\frac{d F}{F} \widehat{s}=C\left\|d \varepsilon^{\mathrm{p}}\right\|\left(\frac{\bar{\sigma}}{R}-\frac{\widehat{s}}{\chi}\right)+d \alpha+\frac{d F}{F} \widehat{s} .
$$

For rock material, the study on cyclic loading and dynamic problems should adopt kinematic hardening or mixed hardening [25]. For better reflecting the dynamical characteristics of rock, the nonlinear kinematic hardening criteria are adopted for kinematic hardening $\alpha$ referring to metallic materials [26]. That is,

$$
d \alpha=\alpha\left(\frac{\gamma F(\partial f / \partial \overline{\boldsymbol{\sigma}})}{\|\partial f / \partial \bar{\sigma}\|}-\alpha\right)\left\|d \boldsymbol{\varepsilon}^{\mathrm{p}}\right\|
$$

where $\alpha$ and $\gamma$ are the material parameters.

Based on the assumptions and demands above, it is concluded that the expression of elastic-plastic matrix is equation (13) according to conformance condition [27]:

$$
\mathbf{D}^{\mathrm{ep}}=\mathbf{D}^{\mathrm{el}}-\frac{\left((\partial f / \partial \bar{\sigma}) \otimes \mathbf{D}^{\mathrm{el}} \otimes \mathbf{D}^{\mathrm{el}} \otimes(\partial f / \partial \bar{\sigma})\right)}{\left\{\partial f /\left\{\partial \bar{\sigma} \otimes \mathbf{D}^{\mathrm{el}} \otimes(\partial f / \partial \bar{\sigma})+\left(\partial f /\left\{\partial \bar{\sigma}\left[\left(\partial F / F \partial \boldsymbol{\varepsilon}^{\mathrm{p}}\right) \widehat{\sigma}+\left(\partial \alpha / \partial \boldsymbol{\varepsilon}^{\mathrm{p}}\right)+U(\widetilde{\sigma} / R)+c(1-R)((\bar{\sigma} / R)-(\widehat{s} / \chi))\right]\right\}\right)\right\}\right\}},
$$

where $D^{\mathrm{ep}}$ and $D^{\mathrm{el}}$ are the elastic-plastic matrix and elastic matrix, respectively. This model differs from the ideal yield surface model because it includes mixed hardening, i.e., the isotropic hardening parameters $H$ and $R$ and the kinematic hardening parameter $\alpha$.

Supposing $\sigma_{2}=\sigma_{3}=0$, then the expression of elasticplastic modulus under uniaxial conditions is

$$
\begin{aligned}
\mathbf{E}^{\mathrm{ep}} & =\mathbf{E}^{\mathrm{el}}-\frac{E^{\mathrm{el}^{2}}(d f / d \bar{\sigma}) \cdot(d f / d \bar{\sigma})}{d f /\left(\left(\mathbf{E}^{\mathrm{el}} \cdot d f\right)+\left(d f /\left(d \bar{\sigma}\left[\left(d F / F d \boldsymbol{\varepsilon}^{\mathrm{p}}\right) \widehat{\sigma}+\left(d \alpha / d \boldsymbol{\varepsilon}^{\mathrm{p}}\right)+U(\widetilde{\sigma} / R)+c(1-R)((\bar{\sigma} / R)-(\widehat{s} / \chi))\right]\right)\right)\right)} \\
& =\mathbf{E}^{\mathrm{el}}-\frac{\mathbf{E}^{\mathrm{e}^{2}}(d f / d \bar{\sigma}) \cdot(d f / d \bar{\sigma})}{\left(\mathbf{E}^{\mathrm{el}} \cdot K+1\right) / K}, \\
K & =d \overline{\boldsymbol{\sigma}}\left[\frac{d F}{F d \boldsymbol{\varepsilon}^{\mathrm{p}}} \widehat{\sigma}+\frac{d \alpha}{d \boldsymbol{\varepsilon}^{\mathrm{p}}}+U \frac{\widetilde{\sigma}}{R}+c(1-R)\left(\frac{\bar{\sigma}}{R}-\frac{\widehat{s}}{\chi}\right)\right] .
\end{aligned}
$$

The elastic-plastic model based on subloading surface is

$$
d \boldsymbol{\sigma}=d \mathbf{E}^{\mathrm{ep}} \cdot d \varepsilon .
$$

\subsection{Subloading Surface Model Based on the Modified} Drucker-Prager $(D-P)$ Criterion. The D-P criterion is widely adopted in rock mechanics and engineering due to its simple form and clear physical meaning, and it also reflects the hydrostatic stress effect and the intermediate principal stress effect. Therefore, it is a beneficial attempt to express the fundamental characteristics of rock under cyclic loading by the relation between the D-P criterion and the subloading surface model.

The expression of the D-P criterion is

$$
f(\sigma)=\beta I_{1}+\sqrt{J_{2}}=F(H)=k(H),
$$

where $\beta$ and $k$ are the material parameters and $I_{1}$ and $J_{2}$ are the first invariant of stress and the second invariant of 
deviator stress, respectively. According to the study [28], $k(H)$ can be expressed as

$$
k(H)=\frac{\sqrt{3} \cos \varphi}{\sqrt{3+\sin ^{2} \varphi}}\left(c+H \varepsilon^{\mathrm{p}}\right),
$$

where $c$ and $\varphi$ are the cohesion and internal frictional angle, respectively. To consider different strength properties of rock under triaxial compression and triaxial tension, namely, the stress angle effect, the smooth ridge model $g(\theta)$ is introduced, where $\theta$ is the Lode angle. The smooth ridge model $g(\theta)$, also referred to as the shape function, represents the shape of failure condition. According to the study [29], the smooth ridge model can be expressed as

$$
g(\theta)=\frac{b}{\left[b^{2}+\left(1-b^{2}\right) \sin ^{2}(45-1.5 \theta)\right]^{1 / 2}} .
$$

The modified D-P criterion could be expressed as

$$
f(\sigma)=\beta I_{1} g(\theta)+\sqrt{J_{2}}=g(\theta) \frac{\sqrt{3} \cos \varphi}{\sqrt{3+\sin ^{2} \varphi}}\left(c+H \varepsilon^{\mathrm{p}}\right) .
$$

\section{Coal Dynamic Damage Experiment}

3.1. Sample Preparation and Experimental Equipment. In order to ensure the consistency in the homogeneity of samples and the stress environment, this study sampled large coal blocks from the same coal seam and the same region. Standard cylindrical samples $(50 \mathrm{~mm} \times 100 \mathrm{~mm})$, numbered as A1-A6, were processed in the laboratory along the vertical bedding direction. The flatness deviation of the end face was controlled in the range of $<0.05 \mathrm{~mm}$, and the diameter deviation of the upper and lower end faces was less than $0.02 \mathrm{~mm}$.

The experiment was carried out on the MTS Landmark 370.50 dynamic and static load testing machine, as shown in Figure 2. For the test machine, the rated static and dynamic loads are $\pm 500 \mathrm{kN}$, the fatigue frequency is $0.1 \mathrm{~Hz}-600 \mathrm{~Hz}$, and the sampling frequency is $122 \mathrm{kHz}$. It not only provides sine waveform, triangular waveform, square waveform, and combined waveforms but also boasts a programming window for personalized experiments. The above parameters fully meet the experimental requirements.

\subsection{Experiment Design}

3.2.1. Experiment Loading. The load used in the experiment was the disturbance load generated in the coal body when the mining machinery works. The Hilbert spectrum of loading signals was obtained by the Hilbert change, as displayed in Figure 3. It can be found that the disturbance loading mainly concentrates in the range of $7-12 \mathrm{~Hz}$. Besides, based on the wave equation, the disturbance loading can produce $15 \mathrm{kN}$ stress in the cylindrical sample.

3.2.2. Experimental Process. To obtain the full stress-strain curve of cyclic loading and verify the model in Section 2, the cyclic loading experiment of axial stress control was performed. First, the sample was loaded to $6 \mathrm{kN}$ by means of ramp loading. Then, the sample was cyclically loaded by an axial stress controlled sine wave with a loading frequency of $10 \mathrm{~Hz}$, a maximum load of $\sigma_{\max }=21 \mathrm{kN}$ (85\% of the uniaxial compressive strength which enables the sample to enter the threshold of cyclic failure) and a minimum load of $\sigma_{\min }=6 \mathrm{kN}$.

3.3. Experimental Results. The stress-strain curves of 6 samples obtained in the experiment were processed into 3 typical curves, as presented in Figure 4 . The 3 curves possess similarities in three aspects. (1) During cyclic loading, the stress-strain curves form a continuous hysteresis loop which generally presents the change rule of "sparse-compactnesssparse". (2) Deformation of coal samples under cyclic load can be divided into three stages, namely, the deformation deceleration stage, the uniform deformation stage, and the acceleration stage. The gradual accumulation of the above three stages of deformation eventually leads to the instability of the samples. (3) It is found that small particles fall off the coal samples, and the samples undergo peeling and destruction in layers. The three curves also demonstrate differences in two aspects. (1) The ends of the curves differ significantly. To be specific, Curve I does not show the damage, Curve II presents the complete failure process, and Curve III reflects that the damaged samples still have the capacity of being loaded and to form hysteresis loops. (2) The area of the hysteresis loop is different, which suggests that the energy of plastic deformation consumption differs. Figure 5 shows that the damage degree of sample becomes higher with the increase of the area of the hysteresis loop.

3.4. Calculation of Model Parameters. According to Section 2, the subloading surface model based on the modified D-P criterion contains 12 parameters: $E, \mu, c, \varphi, b, \theta, H, \alpha, r, u, C$, and $\chi$. Among them, $E, \mu, c, \varphi, b$, and $\theta$ can be determined based on the static uniaxial test and boundary conditions. The hardening parameters $H, \alpha$, and $r$ can be obtained according to the stress-strain curve. The parameters $u, C$, and $\chi$ are unique parameters of the subloading surface model. $u$, which can be preliminary determined on the slope of the medium deformation stress-strain curve, is the parameter that controls the rate of force point to the normal-yield state; $C$ determines the width of the loop; $\chi$ is the ratio of maximum similarity center yield surface to the normal-yield surface, and its value is smaller than 1 . Since $u$ and $C$ shares a crossover, they can only be determined by the method of trial and error, and they have to be adjusted continuously until the stress-strain curve is well fitted based on the results.

In this paper, the parameters $\mu, c, \varphi, b$, and $\theta$ are determined through the analysis of static experiments, while the elastic modulus $E$ is determined by cyclic loading. The hardening parameters $H, \alpha$, and $r$ are determined by adopting the nonlinear random hardening criterion, as listed in Table 1. Assuming that the test material is a standard sample with good uniformity, then the values of $u$ and $C$ ( 80 and 10, respectively, after the trial and error selection) of the 


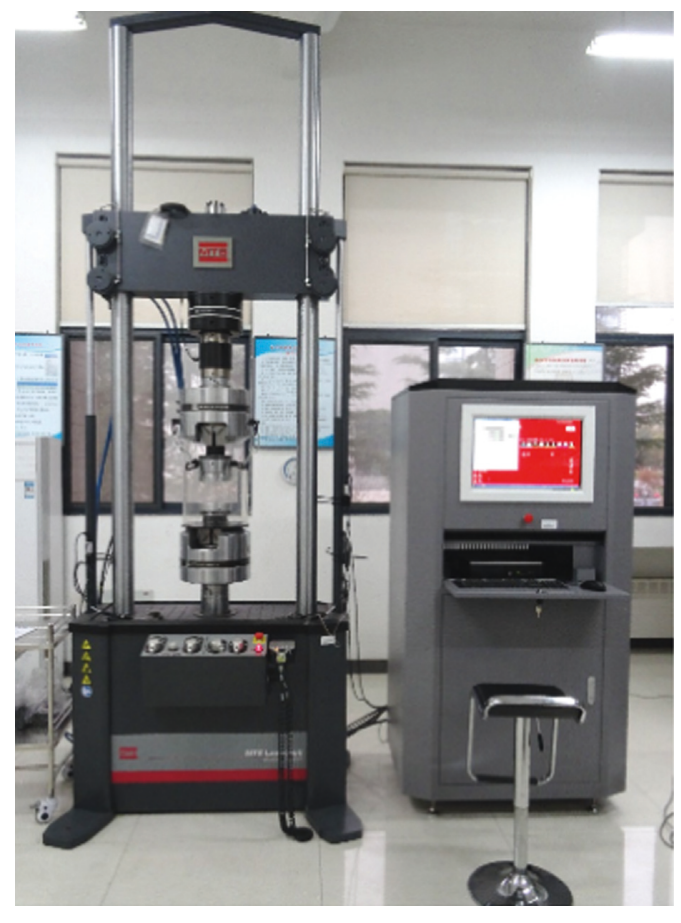

(a)

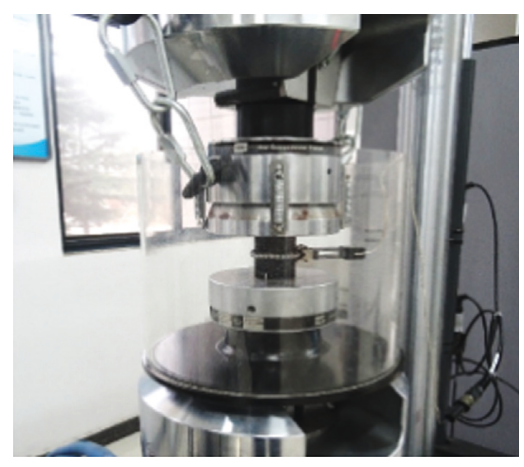

(b)

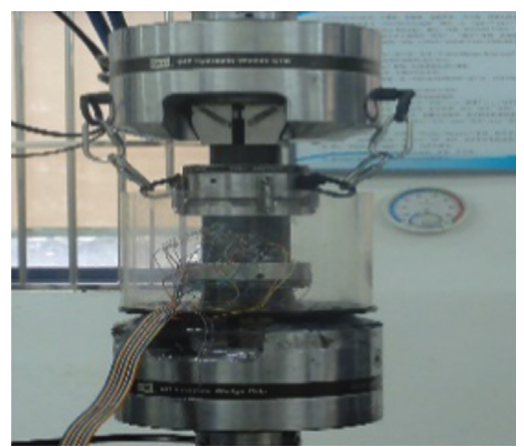

(c)

FIgURE 2: MTS Landmark 370.50.

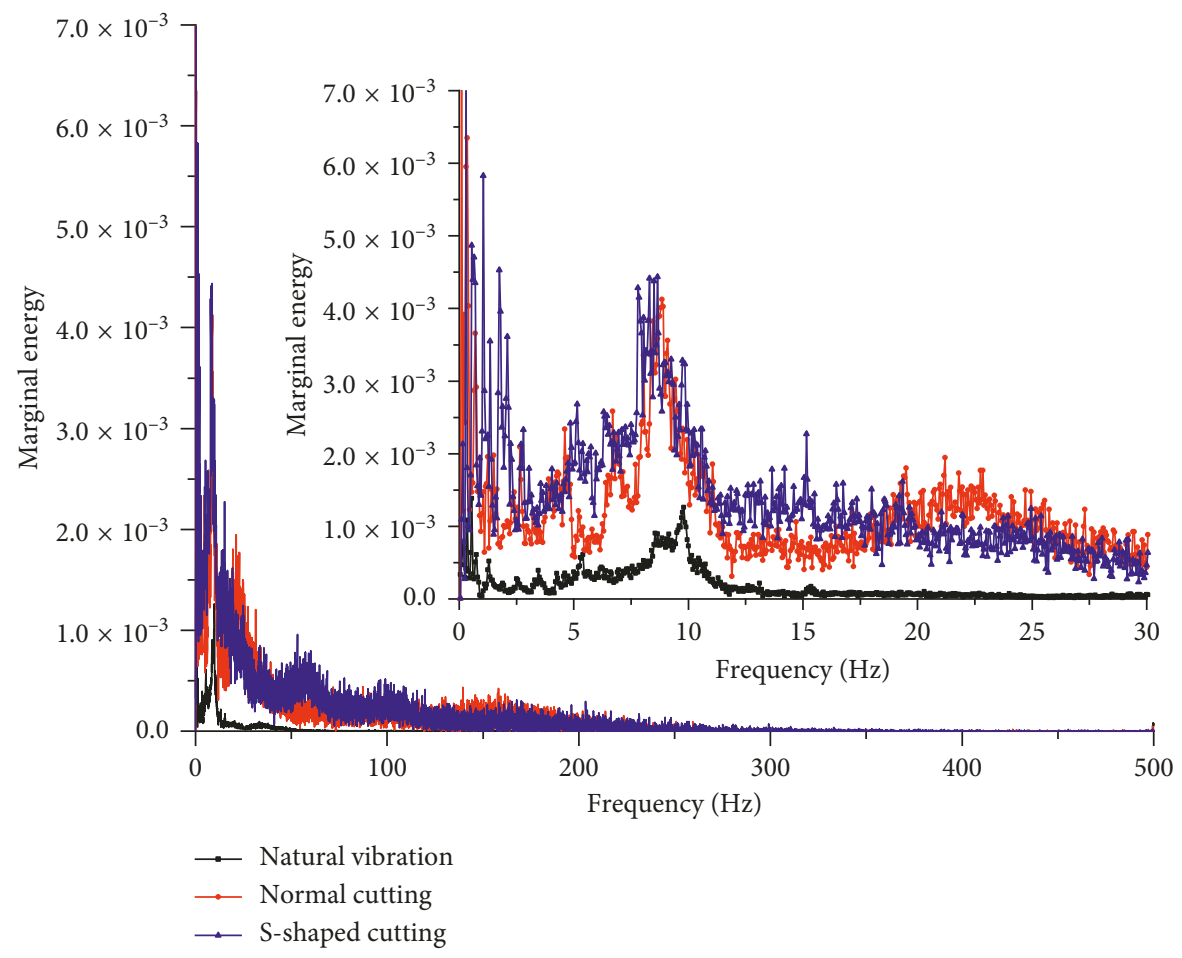

FIgURE 3: Hilbert spectrum of loading.

6 samples are the same. The value of $\chi$ can be obtained from the fitting curve. The specific parameters are given in Table 1, and the fitting effect is displayed in Figure 5. In Figure 5, plastic deformation occurs in both unloading and loading processes, thus forming a hysteresis loop, which indicates that the model can reflect the Mancin effect of coal. With the 


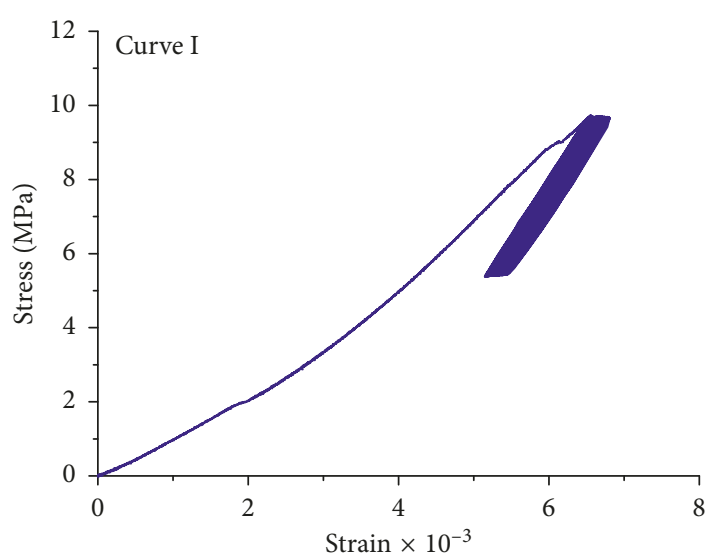

(a)

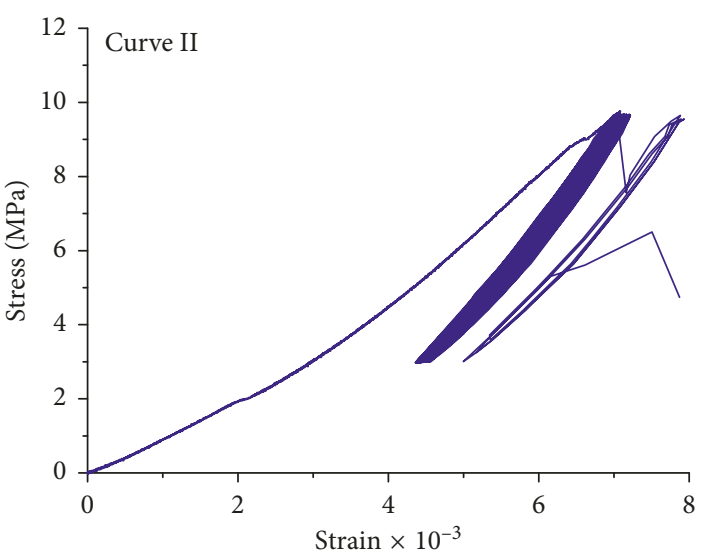

(b)

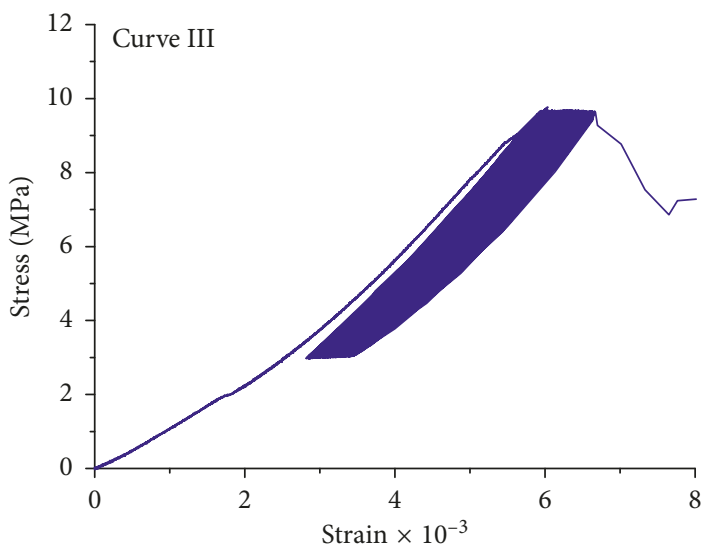

(c)

FIGURE 4: Cyclic loading stress-strain curve of the cylinder sample.

increase of loading time, the accumulative plastic strain also increases correspondingly, indicating that the model can also reflect the coal ratcheting effect. The initial stage of the unloading curve is elastic rebound, and plastic deformation occurs when the unloading reaches a certain degree. In the same way, the initial stage of loading curve is elastic loading, and the plastic deformation occurs when the loading reaches a certain extent. It proves the above conclusion. Therefore, the model undergoes a certain plastic deformation in both loading and unloading processes, which is consistent with the actual deformation characteristics of coal.

\subsection{Discussion of Model Parameter}

3.5.1. Influences of Parameters $u, C$, and $\chi$ on the Model. As unique parameters of the subloading surface model, $u, C$, and $\chi$ exert crucial influences on the model results. Based on the above parameters, the influences of $u, C$, and $\chi$ on the subloading surface model can be obtained by changing their values, respectively, as shown in Figure 6.

Figure 6(a) shows that $\chi$ basically does not affect the loading slope, but it affects the size of the hysteresis loop and the cumulative plastic strain. The larger the value of $\chi$ is, the greater the plastic strain will be. The parameter $C$ affects the modulus of coal. The smaller the value of $C$ is, the smaller the modulus will be and the larger the cumulative plastic strain will be; meanwhile, the cumulative plastic strain and the size of hysteresis loop will increase accordingly. The parameter $u$ has a similar influence on the plastic modulus to the parameter $C$, but its influence is larger. When the value of $u$ drops to a certain degree, the cumulative plastic strain jumps significantly and the size of the corresponding hysteresis loop grows rapidly with the increase of loading time.

3.5.2. Solution of Similarity Ratio $R$. $R$ can be solved with the formula $R=f(\widehat{s}) / F(H)$. Since the formula $\widehat{\sigma}=\widetilde{\sigma}+R \widehat{s}$ includes $R$, the solution can be found by combining the two formulas:

$$
\begin{aligned}
f(\widehat{\sigma}) & =f(\widetilde{\sigma}+R \widehat{s})=\operatorname{atr}(\widetilde{\sigma}+R \widehat{s}) g(\theta)+\sqrt{1 / 2}\left\|\widetilde{\sigma}^{\prime}+R \widehat{s}^{\prime}\right\| \\
& =R F(H) g(\theta),
\end{aligned}
$$

where tr means trace.

The value of $R$ can be obtained by transforming equation (20):

$$
R=\frac{-b+\sqrt{b^{2}-4 a c}}{2 a}
$$

and 

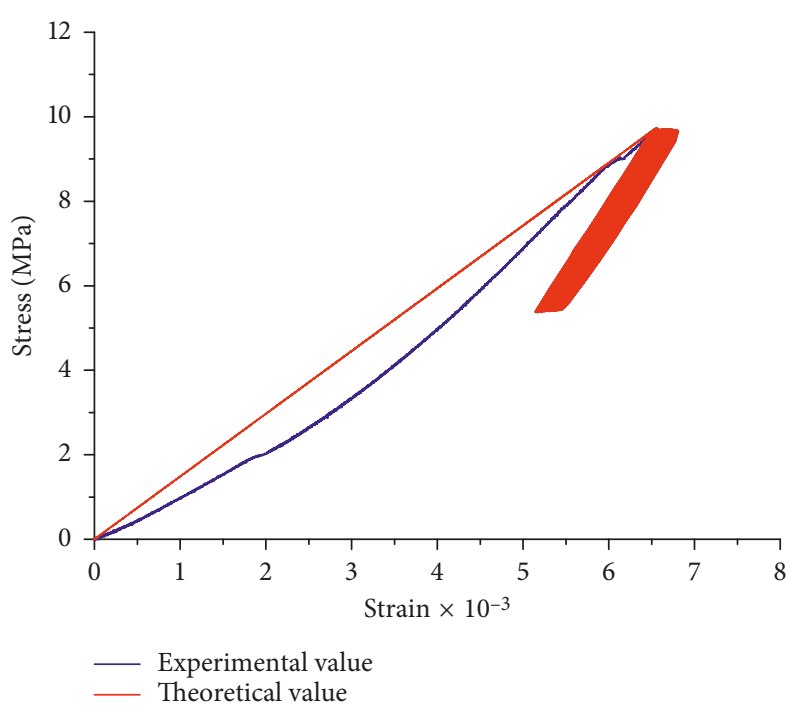

(a)



Experimental value
Theoretical value

(c)

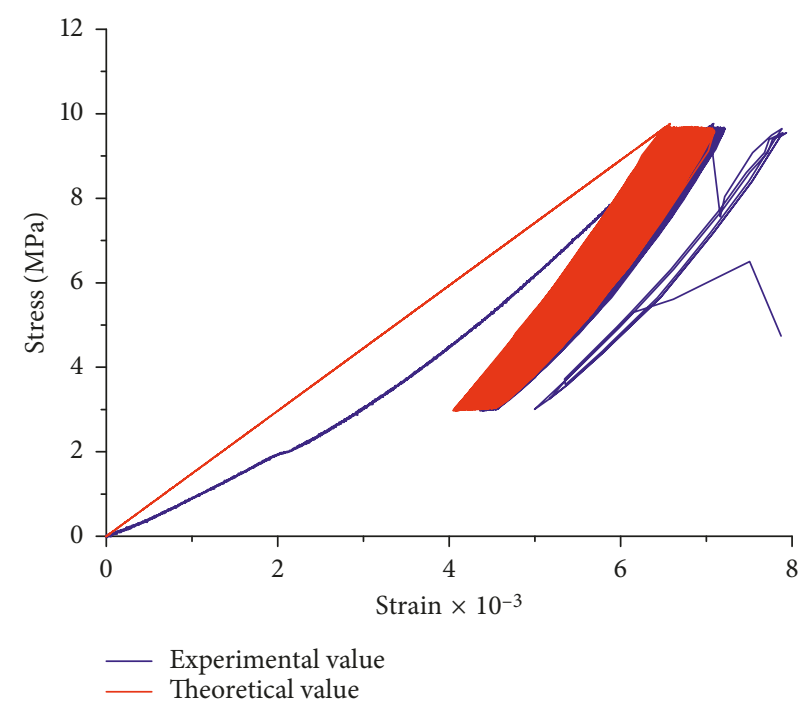

(b)



(d)

FIgURE 5: Experimental and theoretical values.

$$
\begin{aligned}
& a=g^{2}(\theta) F^{2}(H)-6 F(H) g^{2}(\theta) \alpha \widehat{s}_{\mathbf{m}}+9 g^{2}(\theta) \alpha^{2} \widehat{s}_{\mathbf{m}}^{2}-\frac{1}{2}\left\|\widehat{s}^{\prime}\right\|, \\
& b=-6 F(H) \alpha g^{2}(\theta) \widetilde{s}_{\mathbf{m}}+18 \alpha^{2} g^{2}(\theta) \widetilde{s}_{\mathbf{m}} \widehat{s}_{\mathbf{m}}-\left(\widetilde{\sigma}^{\prime} \otimes \widehat{s}^{\prime}\right), \\
& c=9 g^{2}(\theta) \alpha^{2} \widehat{s}_{\mathbf{m}}^{2}-\frac{1}{2}\left\|\widehat{s}^{\prime}\right\|^{2},
\end{aligned}
$$

where $\widehat{\mathbf{s}}_{\mathbf{m}}$ is the average of $\widehat{\mathbf{s}}$ and $\widetilde{\mathbf{s}}_{\mathbf{m}}$ is the average of $\widetilde{\boldsymbol{\sigma}}$.

The parameters of A3 in Table 1 suggest the variation process of $R$, as shown in Figure 7. It can be found from Figure 6 that (1) $R$ can reflect the loading path of the model. The continuous increase in $R$ in the loading process signifies that the subloading surface tends to come closer to the normal-yield surface; (2) $R$ is becoming smaller and smaller in the unloading process, which means the subloading surface gradually gets farther away from the normal-yield surface; (3) the maximum value of $R$ constantly decreases in the single cycling process because $R_{n}$ is reduced when plastic deformation and damage of the model causes the homothetic center to change constantly to adjust the yield surface of the center.

3.5.3. Analysis of $R, R_{n}$, and $\chi . R_{n}$ is the ratio of homothetic yield surface to normal-yield surface. Then, the damage factor produced by the plastic deformation can be expressed as $D_{n}=1-R_{n}$, where $n$ represents the cycling steps. According to equation (2) and (8), the equivalent stress of the model in normal-yield surface can be expressed as effective stress plus damage stress:

$$
f(\sigma)=R F(H)+D_{n} F(H)=\left(R+D_{n}\right) F(H) .
$$


TABLE 1: Parameters of the subloading surface model.

\begin{tabular}{lcccccccccccc}
\hline No. & $E(\mathrm{GPa})$ & $\mu$ & $C(\mathrm{MPa})$ & $\varphi\left(^{\circ}\right)$ & $b$ & $\theta$ & $H$ & $\alpha$ & $r$ & $u$ & $C$ & $\chi$ \\
\hline A1 & 2.18 & 0.25 & 1.54 & 30.58 & 0.75 & 30 & 1 & 30 & 0.5 & 80 & 10 & 0.08 \\
A2 & 1.86 & 0.25 & 1.54 & 30.58 & 0.75 & 30 & 1 & 30 & 0.5 & 80 & 10 & 0.19 \\
A3 & 1.92 & 0.25 & 1.54 & 30.58 & 0.75 & 30 & 1 & 30 & 0.5 & 80 & 10 & 0.19 \\
A4 & 1.84 & 0.25 & 1.54 & 30.58 & 0.75 & 30 & 1 & 30 & 0.5 & 80 & 10 & 0.22 \\
A5 & 2.14 & 0.25 & 1.54 & 30.58 & 0.75 & 30 & 1 & 30 & 0.5 & 80 & 10 & 0.10 \\
A6 & 1.91 & 0.25 & 1.54 & 30.58 & 0.75 & 30 & 1 & 30 & 0.5 & 80 & 10 & 0.17 \\
\hline
\end{tabular}



(a)



(b)

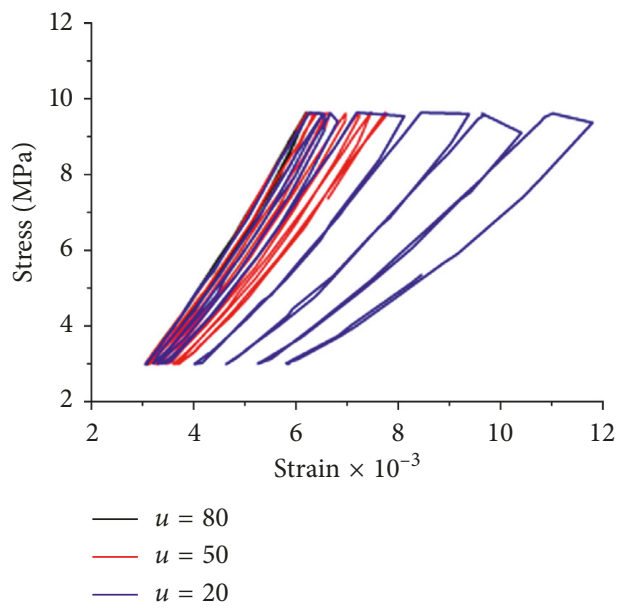

(c)

Figure 6: Influences of parameters on the subloading surface model. (a) Parameter $\chi$. (b) Parameter C. (c) Parameter $u$.

The equivalent stress factor is $R+D_{n}$.

The parameter $\chi$ is the maximum value of the homothetic center $R_{n}$. According to the formula $D_{n}=1-R_{n}, \chi$ represents $\chi=1-D_{n_{\min }}$, which means the parameter $\chi$ is the similarity ratio for the minimum damage (initial damage). The literature shows that coal damage can be expressed with elastic modulus:

$$
D=1-\frac{E^{\prime}}{E}
$$

The elastic modulus $\left(2.37 \times 10^{9} \mathrm{GPa}\right)$ of the model in the static experiment and the parameters $D$ and $\chi$ are shown in Figure 8 . The maximum deviation of $D$ and $\chi$ is no more than $15 \%$; that is to say, they are almost the same. Therefore, it can be concluded that there is a good agreement between the experimental results and the theoretical results.

If plastic deformation occurs within the cycling, that is, if the equivalent stress factor $D_{n}+R=1, R$ reaches to the maximum value in the cycling and the damage factor $D_{n}=$ $1-R_{n_{\max }}$ can be solved through combining equation (21). 


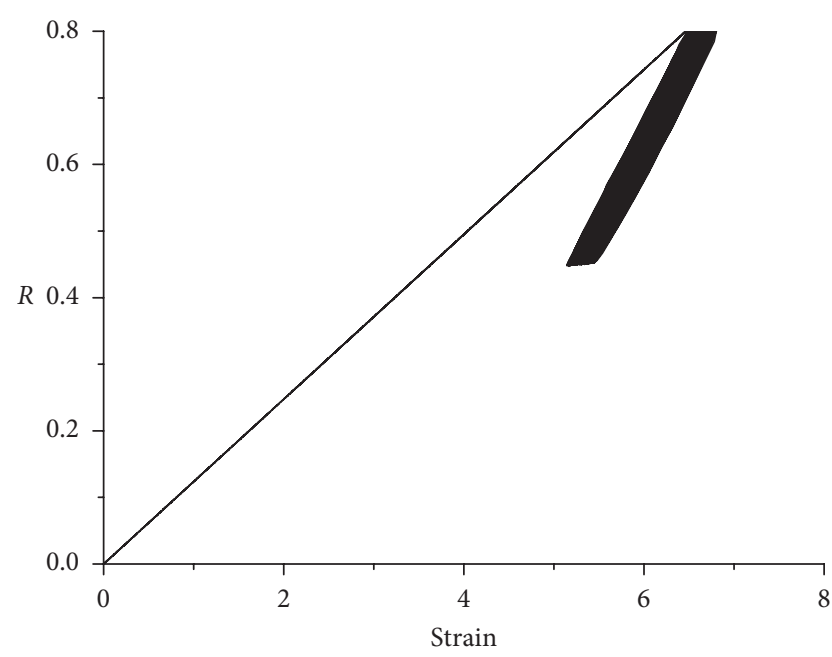

FIgURE 7: Variation of $R$ with strain rate.

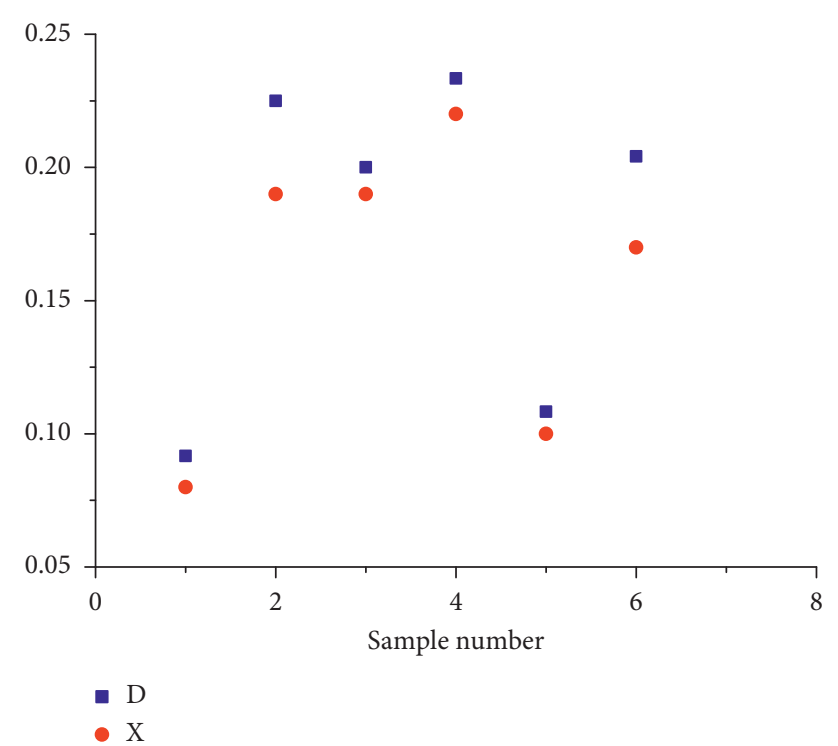

FIgURE 8: Relation between $\chi$ and the elastic model damage.

\section{Analyses of Cyclic Response Characteristics of Fracture Development and Damage in Coal}

In this paper, the stress-strain curves of cylindrical samples were obtained by using the axial force control mode, which verified the rationality of the elastic-plastic model based on subloading surface theory and completed the calculation of the model parameters. In practical engineering, rock can be affected not only by external pressure but also by external displacement. The coal at the coal wall happens to be affected by the movement of the roof and floor so that its stress and strain are constantly changed. There are 3 reasons: (a) the load adopted in this paper is generated by the mining machinery, which directly acts on the roof and floor of coal seam and forces the coal body to deform; (b) what is monitored by the microseismic is the acceleration of coal body which reveals the change in particle displacement; (c) with the increase of coal damage, the stress in coal will not remain constant, but the strain is certain. Therefore, it is more practical to investigate the damage of coal under strain control. Given the fact that the cylindrical coal sample is stripped layer by layer under cyclic loading and cannot maintain good integrity, the cubic sample is chosen as the sample for the coal damage experiment.

Compared with cylindrical samples, cubic samples can bear more deformation and load and allow the observation of more experimental phenomena. According to the observation in the coal mine, the coal on the coal wall is in the limit equilibrium state in many places, such as the occurrence of coal wall slice and shock bumps. For exploring the effect of working disturbance on coal in the limit equilibrium state, the external interface of the testing machine was used to program and control the experimental process. The secant modulus of the sample was calculated in real time. The initial state of the sample was loaded to the point where the secant modulus decreased; that is, the sample entered the yield section, after which the load disturbance of strain control was carried out. The cube sample size was $100 \mathrm{~mm} \times 100 \mathrm{~mm} \times 100 \mathrm{~mm}$, and the disturbance load was a sine wave with a frequency of $10 \mathrm{~Hz}$. The disturbance strain was divided into three levels, namely, $0.5 \%$, $1 \%$, and $1.5 \%$, respectively.

\subsection{Cyclic Response Characteristics of Sample under Strain Load Disturbance}

4.1.1. Fracture Development and Mechanism Analysis. The stress-strain curve of cubic samples under cyclic loading is exhibited in Figure 9 where blue represents strain and yellow represents stress. Three-stage loading experiments were carried out; Figures 9(a) and 9(b) show the strain changes from $0.5 \%$ through $1 \%$ to $0.5 \%$, and Figures 9 (c) and 9 (d) show the strain changes from $0.5 \%$ through $1 \%$ o to $1.5 \%$. In the process of loading, the bearing capacity of the sample decreases first and then remains stable, which suggests that the strain disturbance will cause damage to the coal sample. Besides, specific strain disturbance will only cause a certain damage, which is different from the specific stress disturbance. This is because the specific strain disturbance will only produce a certain amount of plastic deformation, and the specific stress will cause the coal to undergo continuous plastic deformation. At the same time, it is found that when the small strain disturbance changes to the large strain disturbance, the stress of the sample will increase suddenly so will the elastic modulus, showing a certain hardening effect. This demonstrates that the current stress does not reach the ultimate strength of coal failure, and the damage of coal indeed belongs to continuous fatigue damage. Moreover, the bearing capacity of the sample decreases with the increase of disturbance strain, and the larger disturbance will make the coal suddenly lose its bearing capacity, as shown in Figure 9 (d). It is necessary to pay attention to the influence of larger disturbance so as to prevent the instability of coal 




(a)

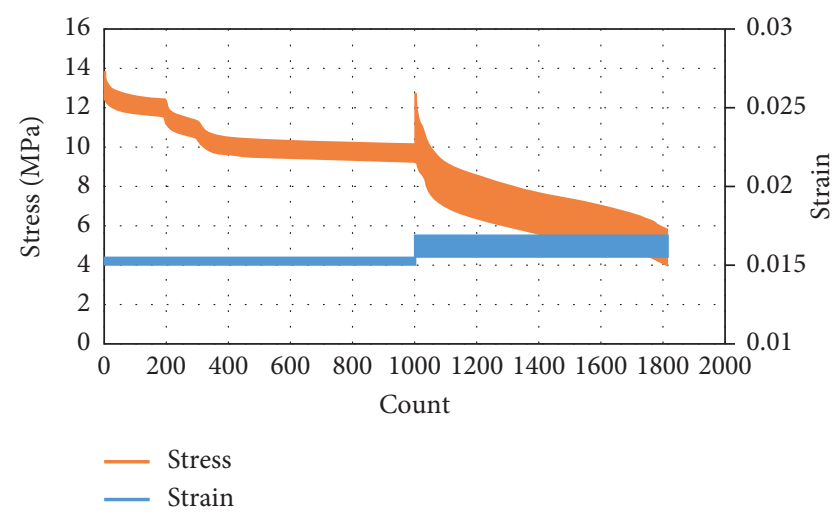

(c)

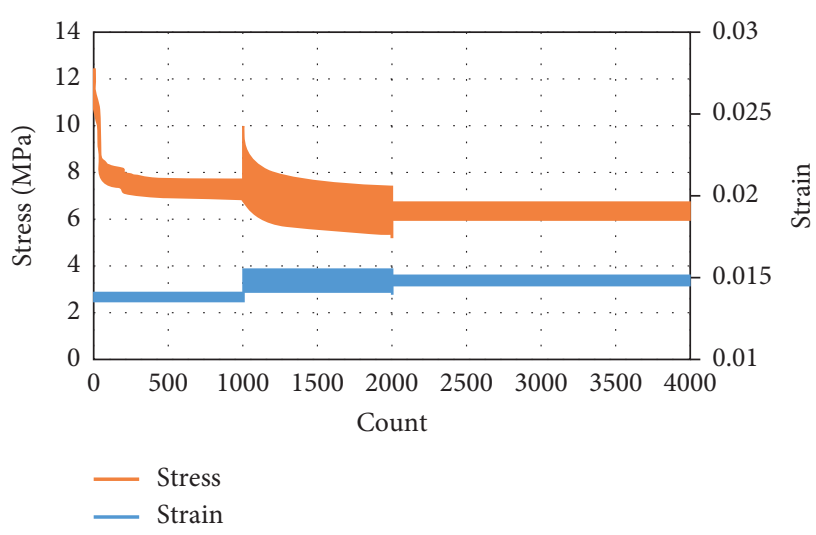

(b)

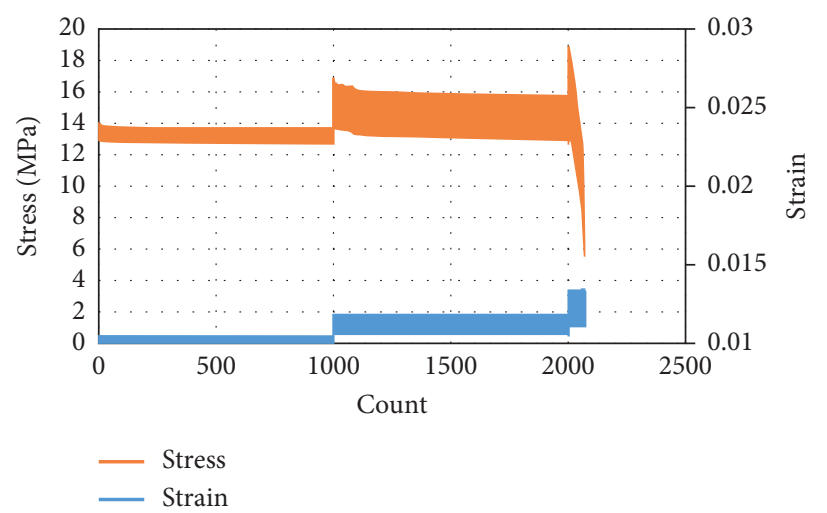

(d)

FIGURE 9: Typical stress-strain curves in the experiment.

body and even the formation of coal burst. After a large strain disturbance, the smaller disturbance can no longer cause further damage to the sample and the load-bearing capacity of the sample will remain at a certain level, showing residual strength characteristics of the raw coal sample. Finally, according to the experimental results, the sample does not suffer sudden damage within the influence range of mining machinery disturbance, but the disturbance will cause fatigue damage to coal, which is not conducive to the control of coal wall. Therefore, the disturbance effect of mining machinery should be fully considered in the control of accidents such as slice wall and roof fall.

4.1.2. Change of Hysteresis Loop. The area of hysteresis loop represents the energy dissipation of the stress cycle. In the process of cyclic loading, there exists a plastic deformation hysteresis loop in each loading or unloading cycle. Taking the curve of Figure 9(c) as an example, the area of hysteresis loop is very large at the beginning of unloading because the friction, propagation, and closure of original microcracks in the sample consumes energy under compression. As the number of cycles increases, the area of hysteresis loop decreases and tends to be stable, as shown in Figure 10, because the extention of original cracks and the generation of new cracks become less and less with the increase of the number of cycles. As a result, the system gradually becomes stable.

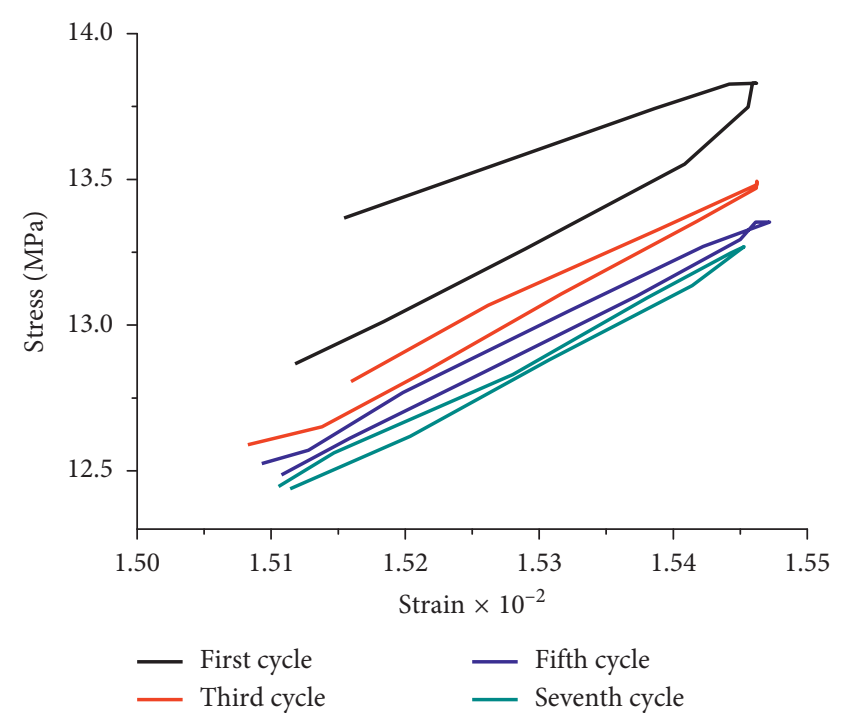

FIGURE 10: Four stress-strain curves showing the hysteresis loops for the initial several loading-unloading cycles at the beginning of a cyclic loading test.

When the disturbance strain increases, the area of hysteresis loop grow suddenly because the new cracks generated under high stress consumes vast energy. As the number of cycles increases, the area of hysteresis loop 
gradually decreases and then tends to be stable. However, when the sample approaches fatigue failure, the area of hysteresis loop grows gradually until the sample fails because considerable crack initiation, extension, and connection and large plastic deformation consume energy sharply, as shown in Figure 11. Limited plastic deformation will occur in each loading cycle, which results in the constant adjustment of the center of subloading surface and the continuous damage of sample.

4.2. Comparison between Damage Parameters. Internal damage is produced when the coal is subjected to frequent and dynamic disturbances of highly static loading. The reasonable definition of the damage variable is useful to analyze its damage state. Each disturbance can be considered as a process of damage to the coal, as well as a complete process that the damage variables undergo. Hence, it necessitates the further reorganization to the damage variables during cyclic loading. There are many definitions of damage variable, most of which are focused on effective elastic modulus and plastic deformation damage. The formulas are as follows:

$$
\begin{aligned}
D & =1-\frac{E^{\prime}}{E}, \\
D^{\prime} & =\frac{\varepsilon^{\mathrm{p}}}{\varepsilon}=\frac{\varepsilon-(\sigma / E)}{\varepsilon} .
\end{aligned}
$$

Meanwhile, the model in this paper also puts forward the damage factor $D_{n}$ to represent the damage variable. Here is a comparison and discussion of $D_{n}$.

The damage variables of Curves (b) and (c) in Figure 9 (undamaged and damaged states of the sample) are calculated according to the formulas, and the results are $D$, $D^{\prime}$, and $D_{n}$, as presented in Figure 12. Figure 12(a) shows the following (1) The damage variables calculated through the plastic strain are obviously larger than the other two, and they have larger numerical values, which are inconsistent with the conventional knowledge. (2) The damage variables $D$ and $D_{n}$ are numerically consistent and have the same trend. They both remain stable after a rapid increase in the first and second stages. (3) In the third stage, compared with the damage variable $D_{n}, D$ is more unstable. As a result, engineers can hardly accurately identify coal mass damage and may make wrong judgments on engineering. (4) When small disturbances become large disturbances, the damage variable $D$ exhibits continuity, which suggests that the damage continues to increase. The sudden decrease in the $D_{n}$ value indicates the hardening of coal, which means that the ultimate strength of coal will increase under the impact load. These phenomena are consistent with the understanding that coal strength is higher than static load at high strain rate loading. The comparison between (b) and (a) shows that the second loading stage reflects the failure process of the sample, and both $D$ and $D_{n}$ increase rapidly first, then increase slowly, and finally jumps at a high rate. The increase rate of $D_{n}$ is greater than that of $D$, that is, $D_{n}$ is



FIgURE 11: Change in hysteresis loop after the increase of disturbance stress.

more sensitive to the damage of coal. To sum up, $D_{\mathrm{n}}$ and $D$ show great consistency in reflecting the regularity of coal damage, with little difference in numerical values. When loading path changes, $D_{n}$ and $D$ become inconsistent. $D_{n}$ can accurately reflect the change in loading path, which contributes to grasping the impact time of sudden load on the coal and helps to prevent the damage caused by the impact in advance. However, $D$ fails to reflect the change in loading path accurately. In terms of the damage changing rate of coal failure, $D_{n}$ is more sensitive to coal damage than $D$, which is helpful to find coal damage process in time and avoid the occurrence of patches, so as to keep safe engineering. Therefore, $D_{n}$ boasts advantages in evaluating the coal damage.

\section{Conclusions}

In this paper, the mechanical response of coal under cyclic loading was studied experimentally. The elastic-plastic model of coal was established by combining subloading surface theory with the D-P yield criterion, and it was verified through experiments. In addition, the mechanism of the cyclic loading on coal and the crack development and damage process of the sample were analyzed. The main conclusions are as follows.

Firstly, an elastic-plastic model for cyclic loading on coal was established, and its rationality was verified in this paper. A cyclic loading model of coal was established by combining the subloading surface model with the D-P yield criterion. Among the parameters, $u, C$, and $\chi$ are the unique parameters for the subloading surface model. $u$ is preliminarily determined by the slope rate of the stress-strain curve of medium deformation rate. It is proved by experiments that $\chi$, which can be obtained by the elastic modulus, is the similarity-center ratio for the minimum damage (initial damage). $C$ is determined by the fitting effect. The model well reflects the Mancin and ratcheting effects of coal 




(a)

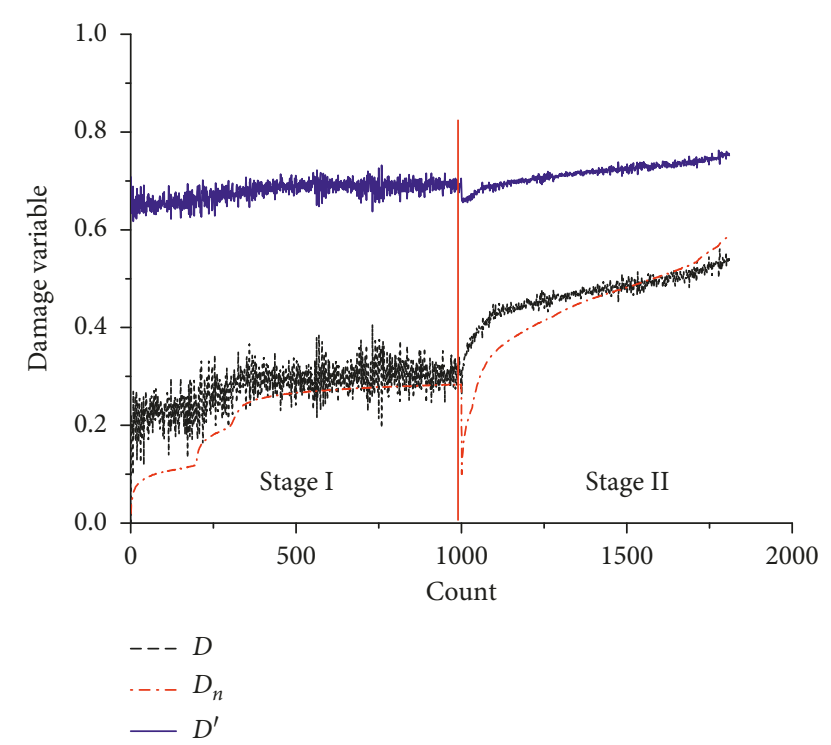

(b)

FIGURE 12: Diagram of comparison between different damage scalars. (a) Undamaged sample. (b) Damaged sample.

samples and is consistent with the actual deformation characteristics of coal. The theoretical value is in good agreement with the experimental value.

Secondly, the cyclic response characteristics of the sample under strain load disturbance were analyzed. Strain disturbance will cause damage to the raw coal sample which has entered the yield stage, and specific strain disturbance will only cause a certain damage to coal, which is different from the specific stress disturbance. The area of hysteresis loop decreases and tends to be stable as the number of cycles increases. When it approaches fatigue failure, the area of hysteresis loop increases gradually until the sample fails.

Finally, the damage variable $D_{n}$ based on coal cyclic loading model was put forward, and the damage variables of different models are compared. Through the comparison of plastic strain and the damage variables calculated with the elastic modulus, it is found that $D_{n}$ can accurately describe the damage process of coal, accurately locate the time point of change in disturbance load, and is more sensitive to coal failure. Based on the features above, it contributes to grasping the impact time of the sudden load on the coal in engineering and preventing accidents such as coal wall rib falling in advance, thus ensuring the safety of projects.

\section{Data Availability}

The data used to support the findings of this study are available from the corresponding author upon request.

\section{Conflicts of Interest}

The authors declare that they have no conflicts of interest.

\section{Acknowledgments}

This research was supported by "The Fundamental Research Funds for the Central Universities" (2017CXNL01).

\section{References}

[1] P. B. Attewell and I. W. Farmer, "Fatigue behaviour of rock," International Journal of Rock Mechanics and Mining Sciences \& Geomechanics Abstracts, vol. 10, no. 1, pp. 1-9, 1973.

[2] Y. Tien, D. Lee, and C. Juang, "Strain, pore pressure and fatigue characteristics of sandstone under various load conditions," International Journal of Rock Mechanics and Mining Sciences \& Geomechanics Abstracts, vol. 28, no. 2-3, pp. 283-298, 1991.

[3] G. Royer-Carfagni and W. Salvatore, "The characterization of marble by cyclic compression loading: experimental results," Mechanics of Cohesive-frictional Materials, vol. 5, no. 7, pp. 535-563, 2000.

[4] K. Fuenkajorn and D. Phueakphum, "Effects of cyclic loading on mechanical properties of Maha Sarakham salt," Engineering Geology, vol. 112, no. 1-4, pp. 43-52, 2010.

[5] J.-Q. Xiao, D.-X. Ding, F.-L. Jiang, and G. Xu, "Fatigue damage variable and evolution of rock subjected to cyclic loading," International Journal of Rock Mechanics and Mining Sciences, vol. 47, no. 3, pp. 461-468, 2010.

[6] N. Erarslan, "Microstructural investigation of subcritical crack propagation and fracture process zone (FPZ) by the reduction of rock fracture toughness under cyclic loading," Engineering Geology, vol. 208, pp. 181-190, 2016.

[7] Y. Guo, C. Yang, and H. Mao, "Mechanical properties of Jintan mine rock salt under complex stress paths," International Journal of Rock Mechanics and Mining Sciences, vol. 56, pp. 54-61, 2012.

[8] S.-Q. Yang, P. G. Ranjith, Y.-H. Huang et al., "Experimental investigation on mechanical damage characteristics of sandstone under triaxial cyclic loading," Geophysical Journal International, vol. 201, no. 2, pp. 662-682, 2015.

[9] F. Trippetta, C. Collettini, P. G. Meredith, and S. Vinciguerra, "Evolution of the elastic moduli of seismogenic triassic evaporites subjected to cyclic stressing," Tectonophysics, vol. 592, pp. 67-79, 2013.

[10] E. Eberhardt, D. Stead, and B. Stimpson, "Quantifying progressive pre-peak brittle fracture damage in rock during 
uniaxial compression," International Journal of Rock Mechanics and Mining Sciences, vol. 36, no. 3, pp. 361-380, 1999.

[11] Z. H. Chen, L. G. Tham, M. R. Yeung, and H. Xie, "Confinement effects for damage and failure of brittle rocks," International Journal of Rock Mechanics and Mining Sciences, vol. 43, no. 8, pp. 1262-1269, 2006.

[12] Z. Wang, S. Li, L. Qiao, and J. Zhao, "Fatigue behavior of granite subjected to cyclic loading under triaxial compression condition," Rock Mechanics and Rock Engineering, vol. 46, no. 6, pp. 1603-1615, 2013.

[13] A. Taheri, A. Royle, Z. Yang, and Y. Zhao, "Study on variations of peak strength of a sandstone during cyclic loading," Geomechanics and Geophysics for Geo-Energy and Geo-Resources, vol. 2, no. 1, pp. 1-10, 2016.

[14] J.-L. Le, J. Manning, and J. F. Labuz, "Scaling of fatigue crack growth in rock," International Journal of Rock Mechanics and Mining Sciences, vol. 72, pp. 71-79, 2014.

[15] M. Ghamgosar and N. Erarslan, "Experimental and numerical studies on development of fracture process zone (FPZ) in rocks under cyclic and static loadings," Rock Mechanics and Rock Engineering, vol. 49, no. 3, pp. 893-908, 2016.

[16] D. R. Groholski, Y. M. Hashash, B. Kim, M. Musgrove, J. Harmon, and J. P. Stewart, "Simplified model for smallstrain nonlinearity and strength in $1 \mathrm{D}$ seismic site response analysis," Journal of Geotechnical and Geoenvironmental Engineering, vol. 142, no. 9, article 04016042, 2016.

[17] N. Erarslan and D. J. Williams, "Mechanism of rock fatigue damage in terms of fracturing modes," International Journal of Fatigue, vol. 43, pp. 76-89, 2012.

[18] M. Karakus, S. Akdag, and T. Bruning, "Rock fatigue damage assessment by acoustic emission," in Proceedings of the International Conference on Geo-Mechanics, Geo-Energy and Geo-Resources (IC3G), pp. 9-82, Melbourne, Australia, September 2016.

[19] J. Xu, S. C. Li, Y. Q. Tao, X. J. Tang, and X. Wu, "Acoustic emission characteristic during rock fatigue damage and failure," Procedia Earth and Planetary Science, vol. 1, no. 1, pp. 556-559, 2009.

[20] Z. Mróz, "On the description of anisotropic workhardening," Journal of the Mechanics and Physics of Solids, vol. 15, no. 3, pp. 163-175, 1967.

[21] W. D. Iwan, "On a class of models for the yielding behavior of continuous and composite systems," Journal of Applied Mechanics, vol. 34, no. 3, pp. 612-617, 1967.

[22] R. D. Krieg, "A practical two surface plasticity theory," Journal of Applied Mechanics, vol. 42, no. 3, pp. 641-646, 1975.

[23] N. Matasovic, "Seismic response of composite horizontallylayered soil deposits,"Dissertation Abstracts International, vol. 54-03, 1554, University of California, Los Angeles, CA, USA, 1993.

[24] K. Hashiguchi, "Tensor analysis," in Elastoplasticity Theory, pp. 1-56, Springer, Berlin, Germany, 2009.

[25] Y. R. Zheng, "New development of geotechnical plastic mechanics-generalized plastic mechanics," Chinese Journal of Geotechnical Engineering, vol. 25, pp. 1-10, 2003.

[26] K. Hashiguchi and S. Tsutsumi, "Elastoplastic constitutive equation with tangential stress rate effect," International Journal of Plasticity, vol. 17, no. 1, pp. 117-145, 2001.

[27] Y. Q. Zhou, Q. Sheng, Z. Q. Zhu, and F. Xiao-Dong, "Subloading surface model for rock based on modified DruckerPrager criterion," Rock and Soil Mechanics, vol. 38, no. 2, pp. 400-408, 2017.

[28] B. Bai, X.-c. Li, L. Shi, W. Yuan, and H.-B. Wang, "A plastic hardening mode based on virtual strength parameters,"
Journal of Yangtze River Scientific Research Institute, vol. 29, no. 8, pp. 24-28, 2012.

[29] M. Aubertin, L. Li, R. Simon, and S. Khalfi, "Formulation and application of a short-term strength criterion for isotropic rocks," Revue Canadienne De Géotechnique, vol. 36, no. 5, pp. 947-960, 1999. 


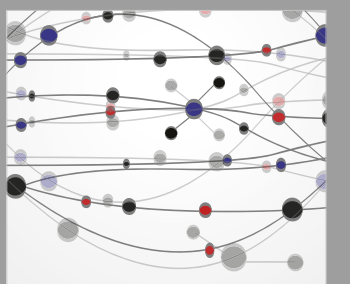

The Scientific World Journal
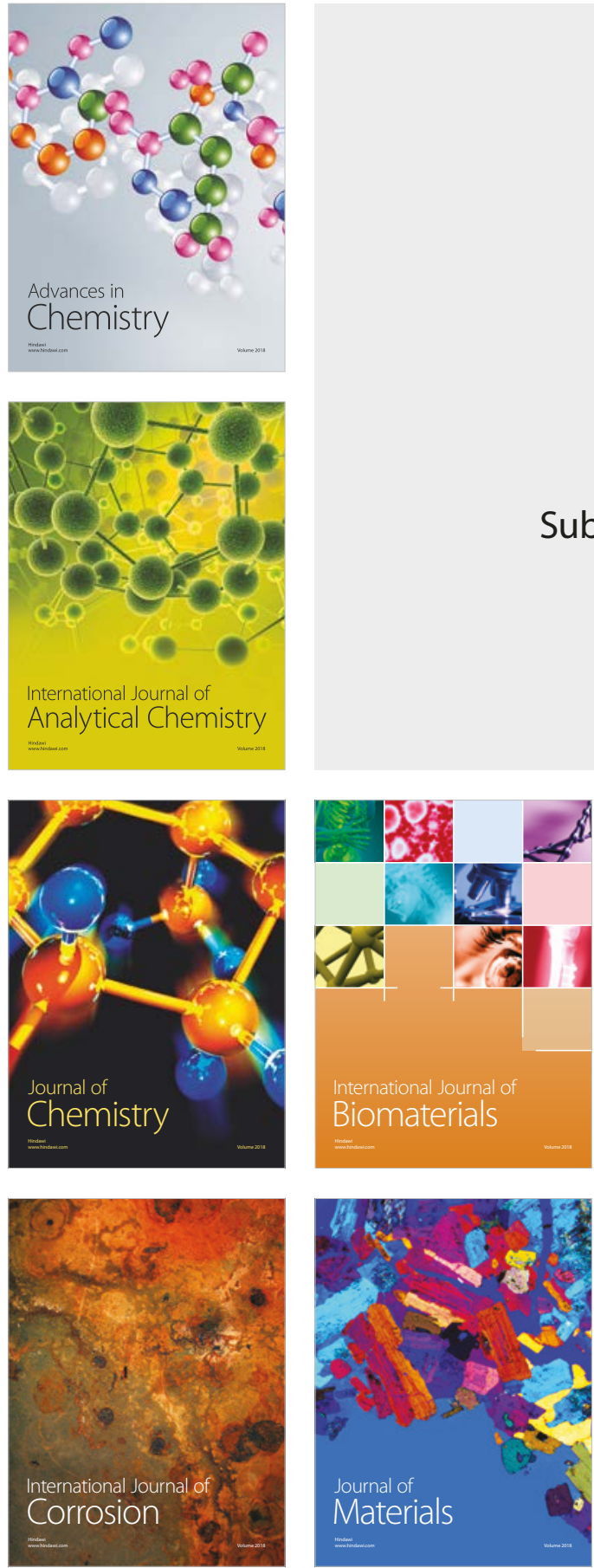

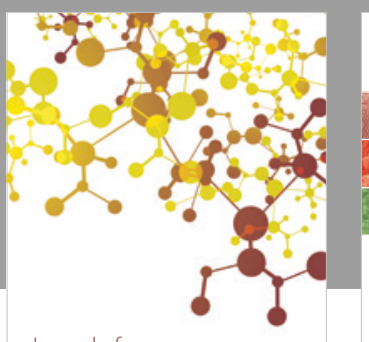

Journal of

Applied Chemistry


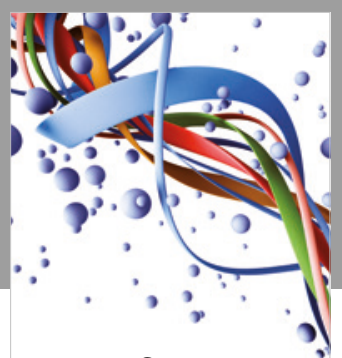

Scientifica

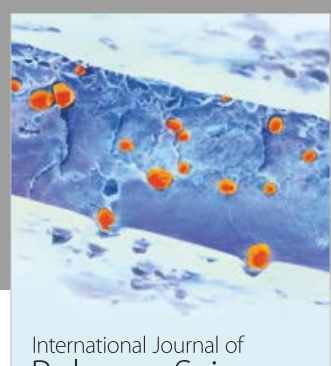

Polymer Science

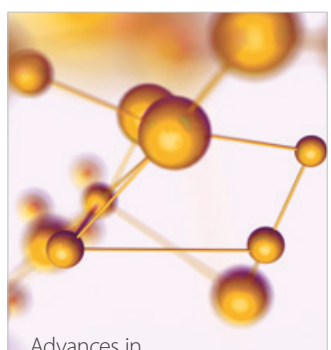

Physical Chemistry
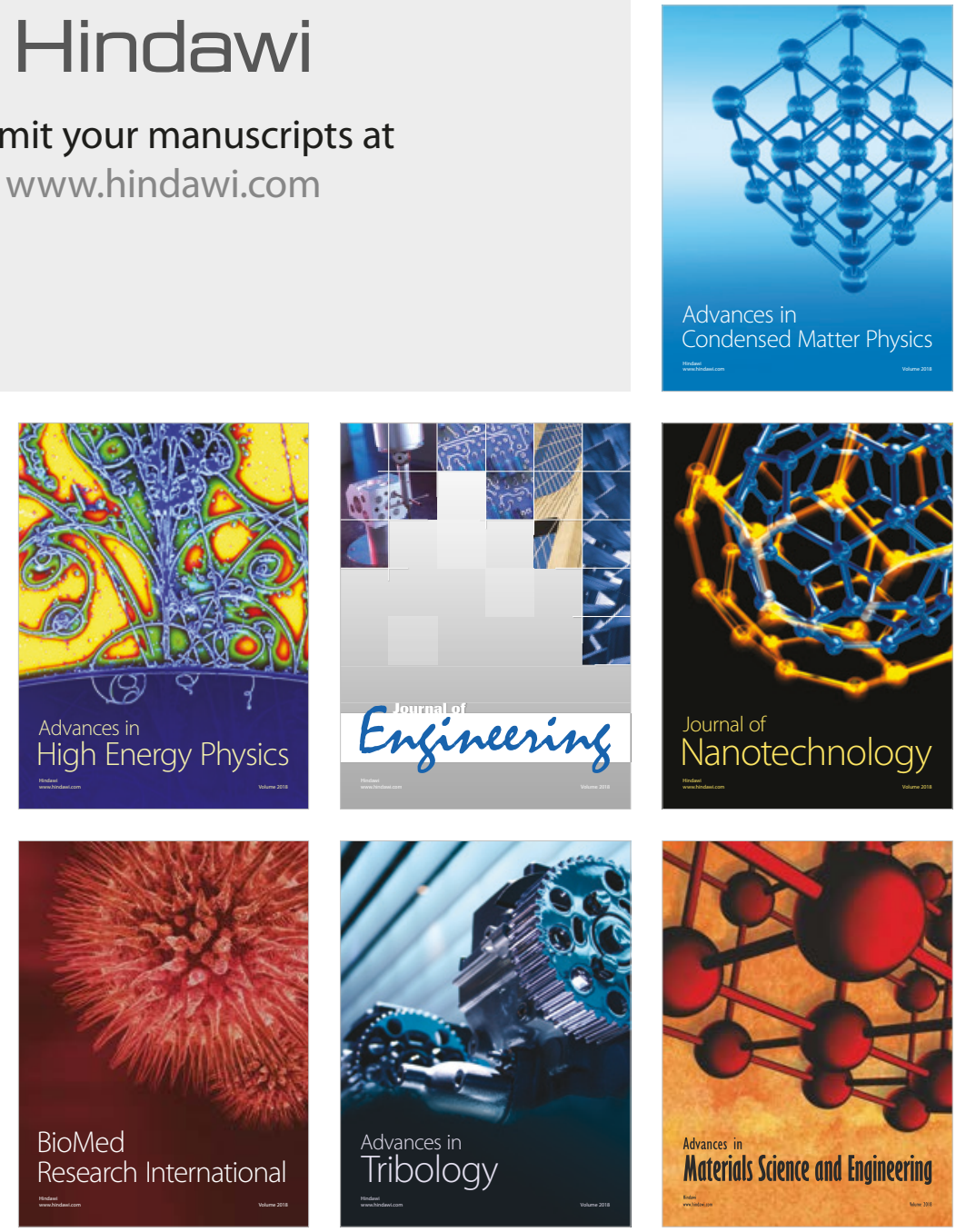